Although the results are interesting, it is a pity that the logic of using knock-in approaches was not continued with the APP gene. Using a humanized knock-in APP sequence would have mimicked the human situation even better. Nevertheless, the results strongly support the pathogenic role of $A \beta 43$ in vivo: the substantial rise in soluble and insoluble $A \beta 43$ apparently caused memory impairment, even in young mice. Notably, relative and absolute levels of $A \beta 42$ and $A \beta 40$ were unchanged in the animals. Thus, the authors concluded that the $A \beta 43$ species might trigger an early Alzheimer's disease-related memory loss in these animals. Finally, Saito et al. ${ }^{3}$ demonstrate a correlation between the steady-state levels of $A \beta 43$ generated by cells expressing different familial presenilin 1 mutant proteins and age of onset in people with the corresponding familial Alzheimer's disease. A similar correlation was found before with $A \beta 42$ (ref. 9), but the new result strengthens the hypothesis that A $\beta 43$ contributes to Alzheimer's disease.

Although this suggestion logically follows the experimental results, one must be cautious regarding extrapolation to human Alzheimer's disease for several reasons. First, despite the confirmed presence of $A \beta 43$ in amyloid plaques of human sporadic Alzheimer's disease and familial inherited Alzheimer's disease associated with APP and presenilin mutations ${ }^{10}$, its concentration is several-fold less than that of $\mathrm{A} \beta 42$ (ref. 11), a predominant species in plaques. Second, $A \beta 43$, let alone its longer precursors, is highly hydrophobic and does not easily leave the cell membrane environment ${ }^{11}$. Thus, the role of $\mathrm{A} \beta 43$ might still be indirect, driving neurotoxicity mostly by acting as a seed that interacts with the more abundant $A \beta$ species. The role of the cell membrane and lipids in this process also remains poorly understood ${ }^{12}$. Finally, the amyloidogenicity of $\mathrm{A} \beta 43$ and $\mathrm{A} \beta 42$ has not been extensively compared ${ }^{10,13}$. Other questions raised by work of Saito et al. ${ }^{3}$ are the extent to which $A \beta 43$ could contribute to the formation of Alzheimer's disease-relevant toxic $\mathrm{A} \beta$ conformers, such as human brain-derived dimers $^{5}$ or amylospheroids 6 , and whether A 343 species may drive both sporadic and familial Alzheimer's disease.

Mechanistically, the question remains how exactly the clinical mutations affect the length of the $A \beta$ peptides. This will need careful measurements of kinetic parameters of the $\gamma$-secretase enzyme and determination of the effect of the mutations on those properties. Such work is only possible with in vitro assays. However, the authors did make a series of intriguing observations in their in vivo experiments. For instance, A $\beta 43$ accumulation was associated with $A \beta 46$ accumulation in homozygous presenilin 1 R278I fibroblasts, corroborating a previously proposed model of tripeptide-wise APP cleavage ${ }^{11,14}$ (Fig. 1). In addition, Saito et al. ${ }^{3}$ investigated an interesting allelic series of fibroblast mutant cell lines. From those experiments, it emerged that the production of $\mathrm{A} \beta 43$ is lower in heterozygous cells that contain one disease allele and one wild-type allele than in cells that contain one disease allele and one knockout allele. The authors suggest that intermediary cleavage products of the consecutive $A \beta$ processing, such as $A \beta 43$, can be transferred to the wild-type allele for further processing (Fig. 1). In the absence of the wild-type allele, processing stops at the $A \beta 43$ form, which is therefore released more abundantly. However, further support for this idea can only come from detailed in vitro kinetic studies.
In conclusion, this study points to the importance of qualitative changes in the $A \beta$ peptide spectrum, as opposed to quantitative changes in total $A \beta$ peptide release, for our understanding of Alzheimer's disease and the role of $A \beta$ peptides in neurodegeneration. The apparent paradox that loss of function of $\gamma$-secretase resulting from clinical mutations ${ }^{15}$ can lead to decreased total $A \beta$ peptide generation while still causing amyloid plaques and Alzheimer's disease can only be resolved if it is accepted that qualitative changes in the $\mathrm{A} \beta$ peptides are more important than quantitative changes. This has obvious implications for drug development.

\section{COMPETING FINANCIAL INTERESTS}

The authors declare competing financial interests: details accompany the full-text HTML version of the paper at www.nature.com/natureneuroscience/.

1. Hardy, J. \& Selkoe, D.J. Science 297, 353-356 (2002).

2. Hardy, J. J. Neurochem. 110, 1129-1134 (2009).

3. Saito, T. et al. Nat. Neurosci. 14, 1023-1032 (2011).

4. De Strooper, B., Vassar, R. \& Golde, T. Nat. Rev. Neurol. 6, 99-107 (2010)

5. Jin, M. et al. Proc. Natl. Acad. Sci. USA 108 5819-5824 (2011).

6. Noguchi, A. et al. J. Biol. Chem. 284, 32895-32905 (2009).

7. Bentahir, M. et al. J. Neurochem. 96, 732-742 (2006).

8. De Strooper, B. et al. EMBO J. 14, 4932-4938 (1995).

9. Kumar-Singh, S. et al. Hum. Mutat. 27, 686-695 (2006).

10. Welander, H. et al. J. Neurochem. 110, 697-706 (2009).

11. Qi-Takahara, Y. et al. J. Neurosci. 25, 436-445 (2005).

12. Martins, I.C. et al. EMBO J. 27, 224-233 (2008).

13. Jarrett, J.T., Berger, E.P. \& Lansbury, P.T. Jr. Biochemistry 32, 4693-4697 (1993).

14. Takami, M. et al. J. Neurosci. 29, 13042-13052 (2009).

15. De Strooper, B. EMBO Rep. 8, 141-146 (2007).

\title{
Reward and autoreceptors
}

Both natural rewards and addictive drugs increase extracellular dopamine (DA) in the striatum. Although studies have found that DA receptors are involved in addiction, the results are conflicting. Susceptibility to drug addiction is correlated with reduced availability of striatal $\mathrm{D}_{2}$ receptors, yet $\mathrm{D}_{2}$ receptor knockout mice show reduced responses to drugs of abuse. These contradictory results may arise because there are two populations of $\mathrm{D}_{2}$ receptors. Most $\mathrm{D}_{2}$ receptors are postsynaptic, responding to DA release from striatal dopaminergic neurons. However, $\mathrm{D}_{2}$ receptors are also expressed presynaptically on DA-releasing neurons (autoreceptors), which exert negative feedback. Previous genetic and pharmacological studies have not been able to differentiate between these two populations of $\mathrm{D}_{2}$ receptors. On page 1033, Bello and colleagues dissect the selective role of $\mathrm{D}_{2}$ autoreceptors and find that deleting $\mathrm{D}_{2}$ autoreceptors increases DA synthesis and release, resulting in increased sensitivity to cocaine.

The authors created mice lacking $\mathrm{D}_{2}$ receptors only in DA-releasing neurons (autoDrd2KO mice). Striatal dopaminergic neurons in autoDrd2KO mice did not show inhibitory currents

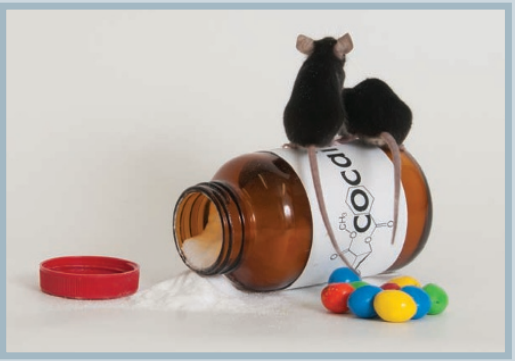
in response to $\mathrm{D}_{2}$ agonists. This lack of negative feedback was accompanied by increased DA synthesis and release. AutoDrd2KO mice were hyperactive, and hypersensitive to cocaine. They exhibited increased cocaine-seeking in a conditioned place preference procedure and worked harder for a food reward in an operant conditioning procedure, suggesting that the role of $\mathrm{D}_{2}$ autoreceptors extends to natural rewards. 